\title{
Smart Irrigation System Using Intelligent Robotics
}

\author{
Pratiksha Pradip Pandao, Abhi Rathi, and Prince Patel
}

\section{ABSTRACT}

To optimize water use for agricultural crops while also verifying water scarcity in the field, an automated irrigation system was developed. Weed management and control are critical for high-yielding, high-quality crops, and developments in weed control technologies have had a significant impact on agricultural output. Any weed control method that is effective must be both durable and versatile. Despite the variety in field circumstances, robust weed control technologies will successfully manage weeds. Weed control technology that is adaptable can change its strategy in response to changing weed populations, genetics, and environmental conditions. The system includes a distributed wireless network of soilmoisture and temperature sensors, as well as conductive sensors in the plant's root zone. Agate way unit also manages sensor data, triggers actuators, and sends data to an Android mobile device. To control water quantity, an algorithm with temperature and soil moisture threshold values was developed and programmed into a microcontroller-based gateway. The added future of this research is that we are utilising a robot to monitor the condition of the crop to see if it is affected by insects or not. The robot will move around the field, and we will be able to track the crop's health on our device.

Keywords: Irrigation, IoT, Robotics, LeenaBOT.

\section{INTRODUCTION}

Smart Agricultural Systems have advanced rapidly in recent decades. Demonstrate the importance of agriculture over the world. In India, for example, over $70 \%$ of the population is reliant on the critical agricultural industry [1]. Irrigation systems in the past relied on mills to water the land using traditional ways without knowing the proper quantities of these crops. These outdated systems are a major source of water waste, resulting in the destruction of some crops due to a lack of sufficient water. However, recent technical advancements have resulted in unique irrigation systems that do not require the farmer to intervene in the irrigation process [2].

Because the Sultanate of Oman is located in an area where there is a lack of rain throughout the year and groundwater, modern irrigation techniques will help to alleviate the problem of water scarcity. Smart systems have demonstrated their ability to regulate crop irrigation. It also assists to reduce irrigation water waste. It will also try to reduce the number of staff, resulting in cost savings [3].

Agriculture is evolving from simple methods of mechanisation in the twentieth century to automation in the twenty-first century. Field operations in the agriculture section are developing, requiring high accuracy in processes to improve output and quality of crops while also controlling production costs. Automation systems must be implemented to meet these requirements. It is critical that the producer studies and actualizes the early framework periods of
Published Online: November 16, 2021

ISSN: $2736-5492$

DOI : $10.24018 /$ ejcompute.2021.1.5.26

\section{P. P. Pandao}

LeenaBOT Robotics pvt Ltd, India.

(e-mail: p3pandao@gmail.com)

A. Rathi

LeenaBOT Robotics Pvt Ltd, India.

(e-mail: abhirathi7409@gmail.com)

P. Patel*

Charotar University of Science and Technology Gujarat, India.

(e-mail: princepatel221375@gmail.com)

*Corresponding Author mechanics in order to reach a high level of automation [4]. In this study, we attempt to address irrigation issues such as farmer errors and excessive water consumption. These inaccuracies have an impact on trees, and their fungus may have an impact on the whole water supply. It is vital to put up effective effort and contribute to the system's desired outcomes. As a result, individual work should not be the sole focus. Farmers must also play a critical role in achieving the high efficiency of contemporary irrigation systems.

The need for agricultural outputs is expanding at a rapid rate as the world's population grows. Furthermore, the farmer's potential and abilities in the agriculture field are dwindling, owing to various enterprises that draw workers away from the farming zone (28 percent of Japanese farmers are over 65 years old) [5]. Agriculture's income must continue to grow since the world's population is expected to rise from 6.8 billion in 2013 to over 10 billion by 2050 . With the decline of a farmer's potential, efficiency becomes a critical requirement [6].

The project's expected outcomes are to make the irrigation system easier to use and understand by constructing and developing the entire automatic irrigation system, as well as to improve crop production by decreasing overwatering from saturated soil. It can prevent irrigation on the wrong day, to switch engine $\mathrm{ON}$ or OFF by using the irrigation system, the controller will operate to switch the engine, so no need for employers, to reduce operational errors caused by employees as much as possible, and to conserve water from waste. 


\section{LITERATURE REVIEW}

\section{A. Sensor Based Automatic Irrigation Management System}

The goal of this research is to develop a technology that aids in the process of water regulation by measuring the humidity ratio. The need for water will be signalled by grounded sensors placed across the land area, and it will be given. At the same time, a mechanical system for filling the water tanker when it is empty was set up [12].

\section{B. Automatic Irrigation System for Sensing Soil Moisture Content}

The goal of this research is to create a system that automatically turns on and off the engine based on moisture. In this regard, I was unable to obtain sufficient information regarding the source of water and the method for managing the withdrawal of water from the supply, as well as information regarding the power supply used in this study [11].

\section{Smart Irrigation System using Arduino}

This technology specializes in the proper application of pesticides in agricultural land in order to combat disease. Flora connected to the sensor and an analytical gadget are included in this machine. A temperature sensor, humidity sensor, motion sensor, light sensor, vibration sensor, and UV sensor are all part of the multi-sensor. The term "sensor" refers to an analytical equipment that analyses a pattern for the presence of a specific substance. The moisture and $\mathrm{pH}$ values observed by the multi-sensor are recorded using an Arduino interface, which is then sent to the farmer's mobile phone through GSM [10].

\section{PROBLEM STATEMENT}

Agriculture is vital to the economies of many countries. To get the greatest results from this study, it's crucial to concentrate on a few key factors like the right quantity of electricity, water supply, and a sufficient watering schedule for the crops. Farmers, particularly those in poverty, are having difficulty reaching these standards. The goal of this project is to create an automated irrigation system that can be operated via a mobile application. This system will operate to reduce the number of workers in a crop field, conserve water and electricity, increase agricultural production with modest amounts of water, reduce manual intervention in watering operations by improving watering speed, and protect plants from fungi. All of these characteristics make this research a viable choice for improving agricultural and irrigation efficiency.

\section{PROPOSED SYSTEM ARCHITECTURE}

Direct watering to the root zone keeps the soil surface dry. Real-time soil moisture and weather monitors - the former via microwave remote sensing — are emerging technologies that could aid with irrigation scheduling. More efficient agricultural water use can also be achieved by rainwater gathering, efficient irrigation water conveyance, and the use of reclaimed water [13]. As illustrated in Fig. 1 and 2, these strategies would be beneficial for both maize and cellulosic ethanol crops.

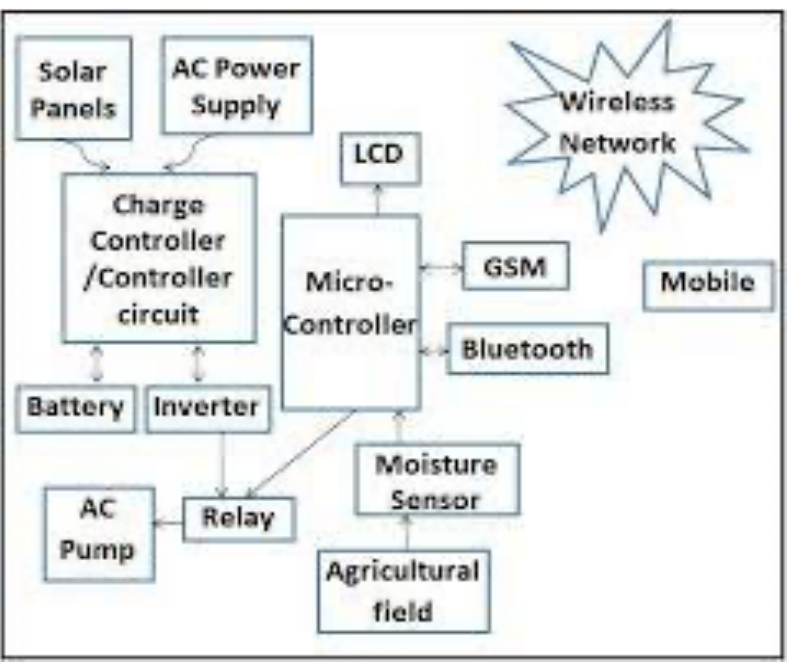

Fig. 1. Block diagram at Irrigation end (user end).

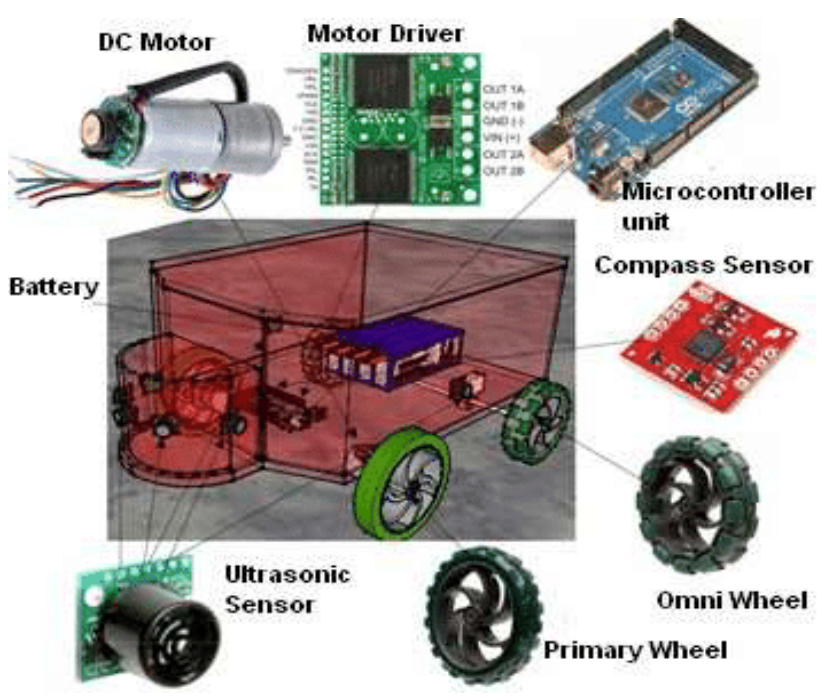

Fig. 2. Block diagram at robot end.

\section{WORKING}

There are two sections to this project. The irrigation part is one part, and the robot part is the other. The irrigation system includes temperature and conductivity sensors, and the microcontroller constantly monitors the temperature and water content of the soil, sending data to the base station via wireless communication; in this case, we're utilising a Bluetooth radio set to do so [14]. The irrigation system has two modes of operation. The first mode is automatic, while the second is manual. In automatic mode, the irrigation motor is controlled by the microcontroller depending on the water content; in manual mode, the motor is controlled by the user command, which can be communicated via Bluetooth communication. The irrigation system always sends the soil parameters to the destination in both modes. We're using a Lpc2148 microcontroller to control the irrigation system, and an HC-05 Bluetooth module to establish a wireless network. The module's operating frequency is $2.4 \mathrm{GHz}$, and the operating voltage is $3.3 \mathrm{~V}$. The reason we chose these modules is that they use less power and have a faster 
execution speed than other processors and radio sets [7]. The second element is the robot section, which comprises a camera and a wireless module that allows us to drive the robot in various directions. As illustrated in Fig. 3, we may monitor and examine the insects in the field using the camera.

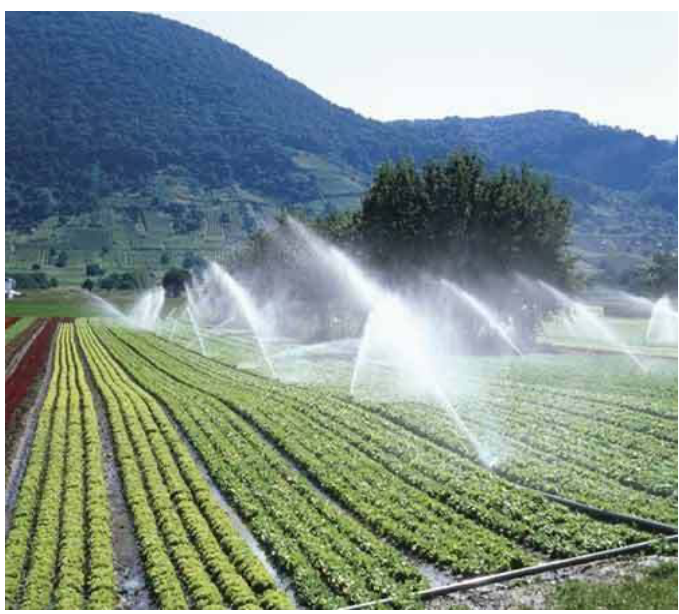

Fig. 3. General view of a field.

\section{A. Irrigation END ARM7 (Lpc2148 Controller)}

Fig. 4 depicts the Lpc2148 Controller, which includes the following features:

- Two UARTs, one with full modem interface.

- Two I2C serial interfaces, Two SPI serial interfaces Watchdog Timer.

- 512KB on-chip Flash ROM with In-System Programming (ISP) and In-Application Programming (IAP), 32KBRAM, Vectored Interrupt Controller.

- Two 10bit ADCs with 14 channels, USB 2.0 Full Speed Device Controller.

- ARM7TDMI-S based high-performance 32-bit RISC Microcontroller with Thumb extensions.

- Two 32-bit timers.

- CPU clock up to $60 \mathrm{MHz}$.

- LPC2148 are based on 16/32 bit ARM7TDMI-S CPU.

- It contains $128 / 512$ kilobytes of embedded high speed flash memory.

- General purpose I/O pins.

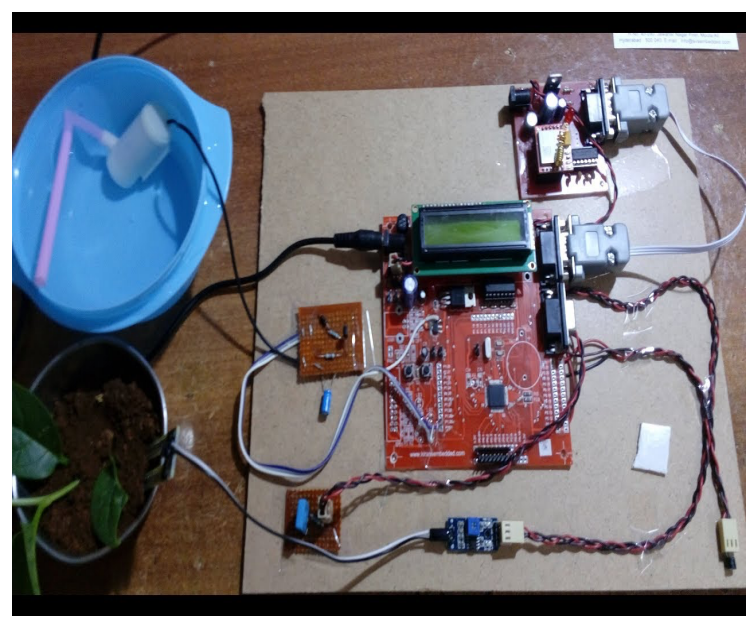

Fig. 4. LPC 2148 Processor.

\section{B. Power Supply}

To reduce $230 \mathrm{v}$ to the required voltage, a step down transformer is needed. Fig. 5 depicts the voltage levels.

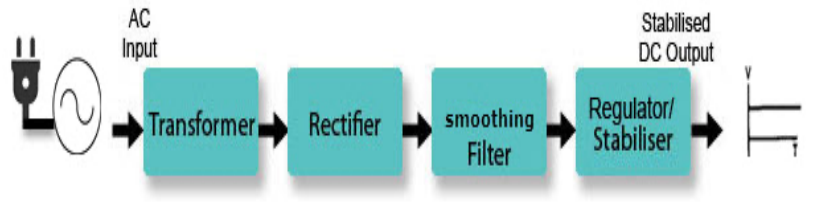

Power Supply Block Diagram

Fig. 5. Block diagram of Power Supply.

\section{Radio Set}

The data is transmitted and received from one end to the other using a radio set. At the irrigation end, we're utilizing the HC-05 Bluetooth module. The HC-05bluetooth module has a $2.4 \mathrm{GHz}$ operational frequency and a $3.3 \mathrm{~V}$ operating voltage. In open space, the Bluetooth module's maximum communication distance is 20 meters. At the robotic end, we'll install an RF module [15]. The A434 MHZ RF module is used at the robotic end. The RF module's working voltage is $5 \mathrm{~V}$, and the RF module's maximum distance in free space is 50 meters. We can alternatively use a ZIGBEE or Bluetooth module at both ends, but we are using the RF module because it is required. We're utilizing two distinct modules to make both devices work at the same time because we can only operate one system at a time with Bluetooth [8].

\section{Sensors}

In our project we are using two sensors.

\section{1) Temperature Sensor}

We use an LM35 temperature sensor to monitor the temperature of the climate. The LM35 sensor has a temperature range of $150^{\circ} \mathrm{C}$ because the highest temperature of the atmosphere is roughly $60^{\circ} \mathrm{C}$ during the summer. A temperature sensor is a gadget that detects temperature fluctuations across it. The LM35 is a simple temperature sensor that can be used for testing. Because its output voltage is linearly related to temperature, it gives values in centigrade (degree Celsius). It makes use of the fact that as the temperature rises, the voltage across the diode rises at a predictable rate (actually the drop across base-emitter junction of transistor). Fig. 6 shows the output of the LM35 sensor, which is $10 \mathrm{mV}$ for every 1 degree centigrade.

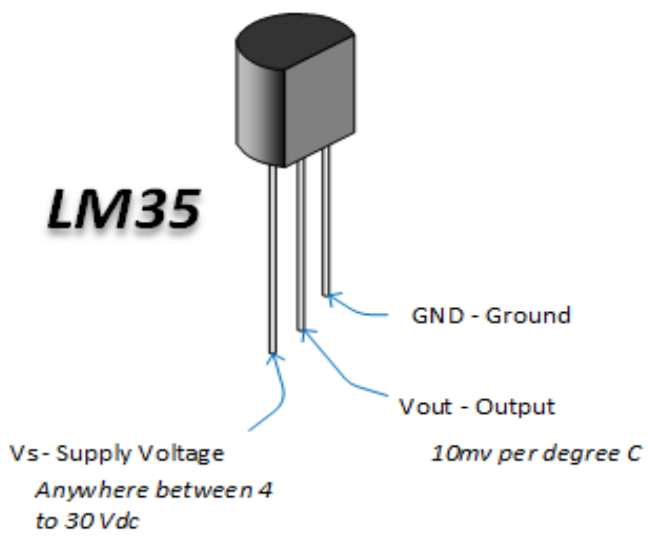

Fig. 6. LM 35 temperature sensor. 


\section{2) Conductive Sensor}

It is also known as a moister sensor, and it is nothing more than two iron rods inserted in the soil that are used to measure the water content in the soil. We apply the $+\mathrm{ve} \mathrm{v} / \mathrm{g}$ to one end and utilise the other terminal as an output terminal. If there is enough water in the soil, conduction occurs between the two terminals, and the output is a +ve v/g [9], as shown in Fig. 7.

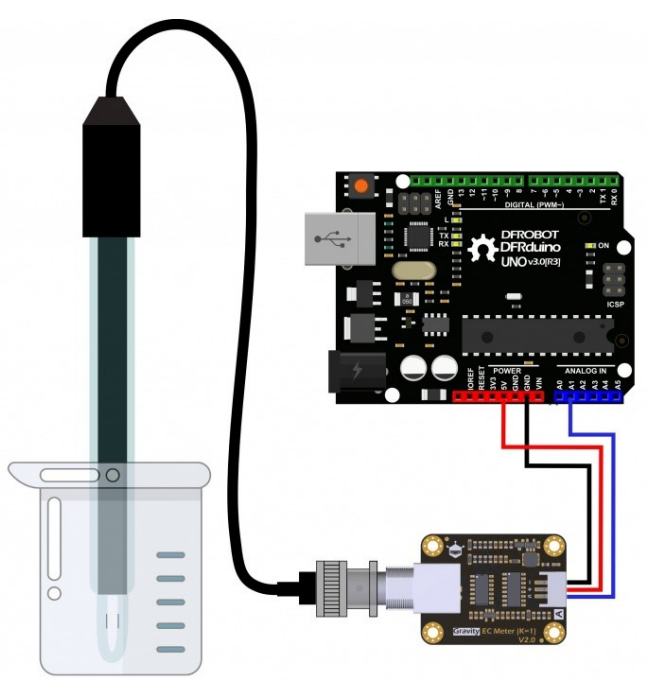

Fig. 7. Conductive sensor.

\section{ROBOT}

We use the robot to check the crop's status by mounting a camera on the robot's head, which allows us to monitor the robot's position as well as the crop's condition on our PC. Because the robot's primary duty is to move around the field and monitor the crop's condition before forwarding the data to the camera, which is controlled by the user, we can utilise an 8051 microcontroller as shown in Fig. 8. In the robotics end, we're also employing a DC motor. The DC motor operates on the electro-magnetic induction principle.

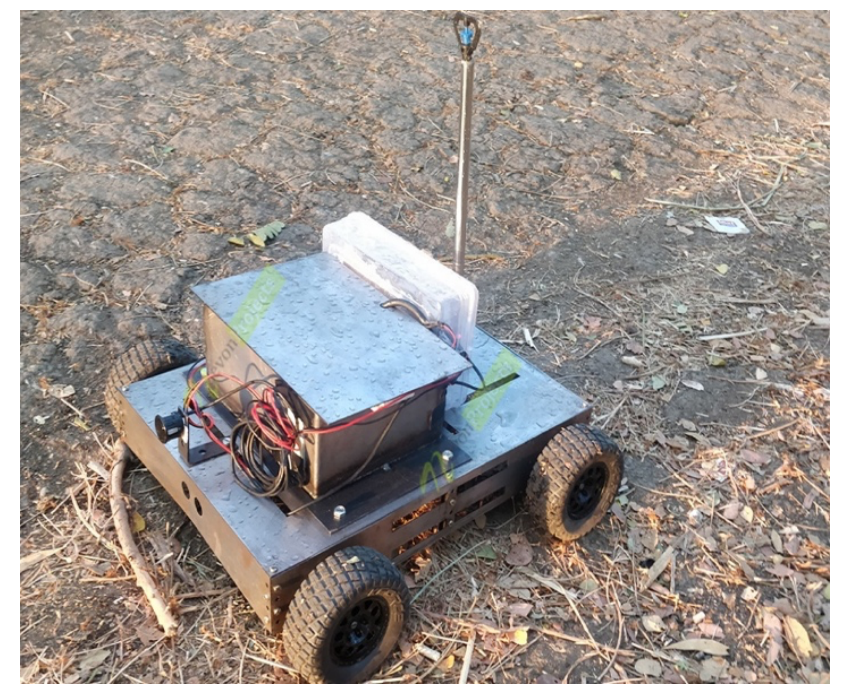

Fig. 8. Automated Irrigation System Using Robotics.

A fully self-contained robot can:

- Learn more about the environment.

- Working without human intervention for an extended period of time
- Without human assistance, move all or part of oneself within its operational environment.

- Unless it is part of its design standards, avoid scenarios that are detrimental to people, property, or itself.

\section{RESULT AND DISCUSSION}

Fig. 9 shows that all of the plants were watered at the same time and in equal amounts almost twice a week, but after comparing the results, we discovered that the lemon and mango plants needed to be watered more than twice a week because the humidity ratio is significantly reduced when temperature and irrigation time are taken into account. Plants lose humidity rapidly and considerably when they irrigate in the morning because they irrigate at the wrong time of day, when the sun evaporates water faster. In the case of the mint plant, we discovered that it does not lose moisture rapidly and can take a longer time of mango and lemon. We may conclude from these findings that employing an automatic irrigation system is more efficient since it eliminates practically all of the drawbacks associated with using a manual system. Because the automatic irrigation system is based on the demands of the plants, it eliminates the problem of irrigation at inopportune times by combining light and temperature sensors.

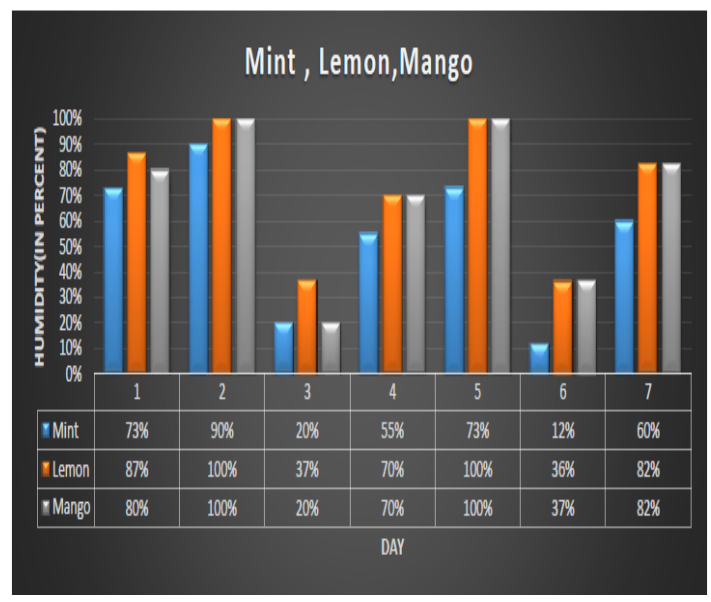

Fig. 9. Humidity data of all plants.

The target was achieved after completing the plan and collecting the components of the smart irrigation system. In addition, all of the requirements were met in order to complete this smart irrigation system and bring it to full production and completion. After that, the system was put to the test, and the ultimate result was exactly what was expected. The system will not function unless two or three moisture sensors from any line of the three fields send a signal to the microcontroller indicating that the soil is dry and that the crop requires water. When the sign reaches the microcontroller, it will send a command to the line field valve's relay to be energized to open the valve, as well as a command to the pump's relay to exchange it straight to irrigate that field. Also, if two or three of the three plants' moisture sensors are operational, all three fields can be irrigated at the same time. As a result, all solenoid valve relays may be triggered, opening all valves and causing the pump to run to water all three plants. Furthermore, this smart 
irrigation system has been set up such that it will not work if it rains, as the rainy sensor will activate and send a signal to Arduino to turn off the water pump and close all valves. Furthermore, the system will not function during the day since the mild sensor will activate during the day, causing the plant's value to be closed and the pump to be turned off.

\section{CONCLUSION}

The system was successfully created for regularly checking the status of the crop by employing a robot that moves around in the field and displays the crop's condition on our PC. The designed automated irrigation system demonstrates that water consumption can be reduced for a given amount of fresh biomass production. Aside from the financial benefits of conserving water, the importance of preserving this natural resource justifies the usage of these irrigation methods. Many issues arose, such as the fact that the tables utilized as the project's foundation were larger than the prototype's required size. In addition, the supplies needed for this project have been tough to come by. The difficulty of selecting the appropriate plant plate to secure it in the foam and artificial grass is a serious one. Furthermore, because a large number of gadgets were linked to the Arduino, wire connections were difficult to make. Furthermore, the project's batteries deplete quickly when in operation, making the system's sequence of events difficult to determine. The controllers for the microcontroller were difficult to design because a single error may cause any electrical component to fail. It was not easy to build the software for the Smart Irrigation System and upload it to a microcontroller to drive the water pump and open valves with eighteen sensors, but the program was done with great results thanks to the microcontroller library.

\section{FUTURE WORK}

With the project's completion, the first step in the future will be to scale up the project. Also, instead of using wires, the device may be controlled by Zig Bee. Furthermore, to develop more responsive mobile applications with better data control. We may also develop this technology by employing renewable energy, such as solar power, rather of batteries, which will assist to lower future costs.

\section{REFERENCES}

[1] Kanade P, Prasad JP. Machine Learning Techniques in Plant Conditions Classification and Observation. 2021 5th International Conference on Computing Methodologies and Communication (ICCMC) IEEE, pp. 729-734, 2021.

[2] Kanade P, Prasad JP. Arduino based Machine Learning and IoT Smart Irrigation System. International Journal of Soft Computing and Engineering. 2021; 10(4): 1-5.

[3] Adeodu AO, Bodunde OP, Daniyan IA, Omitola OO, Akinyoola JO, Adie UC. Development of an autonomous mobile plant irrigation robot for semi structured environment. Procedia Manufacturing. 2019; 35: 9-15.

[4] Reid JF, Zhang Q, Noguchi N, Dickson M. Agricultural automatic guidance research in North America. Computers and Electronics in Agriculture. 2000; 25(1-2): 155-167.

[5] Kanade P, Alva P, Prasad JP, Kanade S. Smart Garbage Monitoring System using Internet of Things (IoT). 2021 5th International Conference on Computing Methodologies and Communication (ICCMC). IEEE. pp. 330-335, 2021.
[6] Kanade P, Kanade S. Medical Assistant Robot ARM for COVID-19 Patients Treatment - A Raspberry Pi Project. International Research Journal of Engineering and Technology. 2020; 7(10): 105-111.

[7] Han D-M, Lim J-H. Smart home energy management system using IEEE 802.15.4 and ZigBee. IEEE Transactions on Consumer. Electronics. 2010; 56(3): 1403-1410.

[8] Gomez C, Paradells J. Wireless home automation networks: A survey of architectures and technologies. IEEE Communications Magazine. 2010; 48(6): 92-101.

[9] Gungor VC, Hancke GP. Industrial wireless sensor networks: Challenges, design principles, and technical approaches. IEEE Transactions and Industrial Electronics. 2009; 56(10): 4258-4265.

[10] Kanade P, Ashwini P. Smart Agriculture Robot for Sowing Seed. International Journal of Engineering Science and Computing (IJESC), 2021; 11(01): 27563-27565.

[11] Kanade P, Alva P. Raspberry pi project - ultrasonic distance sensor in civil engineering. International Journal in IT \& Engineering (IJITE). 2020; 8(10): 1-6.

[12] Carullo A, Corbellini S, Parvis M, Vallan A. A wireless sensor network for cold-chain monitoring. IEEE Transactions on Instrumentation and Measurement. 2012; 61(10): 2787-2798.

[13] Idama O. Uguru H. Robotization of tomato fruits production to enhance food security. Journal of Engineering Research and Reports. 2021; 20(1): 67-75.

[14] Kanade P, Alva P, Kanade S, Ghatwal S. Automated Robot ARM using Ultrasonic Sensor in Assembly Line. International Research Journal of Engineering and Technology (IRJET). 2020; 7(12): 615-620.

[15] Suriyachai P, Roedig U, Scott A. A survey of MAC protocols for mission-critical applications in wireless sensor networks, Common. Surveys and Tutorials. 2012; 14(2): 240-264. 